\title{
Long range electromagnetic cannon
}

\author{
E. Schmidt \& J. Tzeng \\ US Army Research Laboratory, Aberdeen Proving Ground, MD, USA
}

\begin{abstract}
Electromagnetic (EM) railguns offer the potential to fire projectiles at velocities up to $6 \mathrm{~km} / \mathrm{s}$. This could conceivably permit ballistic trajectories to reach very long ranges, perhaps $1000 \mathrm{~km}$ or more. To deliver a payload of interest and survive the aerothermal environment associated with hypervelocity, sea level launch, the projectile would need to be quite large, 500-1000 Kg. This in turn implies a launcher of prodigious size and mass. This paper examines the nature of an electromagnetic cannon required to achieve such capabilities.

Keywords: electromagnetic launch, rail guns, hypervelocity flight, long range artillery.
\end{abstract}

\section{Introduction}

Historically, there has been a continuing interest in long range cannons. During the First World War, Germany [1] employed the $210 \mathrm{~mm}$, K12(E), Paris Gun with a maximum range of $115 \mathrm{~km}$. In the Second World War, they fielded the $800 \mathrm{~mm}$ Gustav cannon with a range of $47 \mathrm{~km}$. The cannon was transported in pieces and assembled on two parallel railway tracks by a crew of 1200 men. Naval artillery also illustrates this trend as the bore size of guns on battleships grew throughout the Twentieth Century culminating in the $460 \mathrm{~mm}$ guns on the Japanese Yamato class with a range of $40 \mathrm{~km}$. With the advances in aircraft and missile capabilities, long range delivery of ordnance became routine and interest in very large calibre guns has waned. However, the cost of missiles and risk of manned delivery are of concern. Thus, worldwide efforts to increase the range of conventional artillery, e.g., $155 \mathrm{~mm}$, have lead to the introduction of technologies such as base bleed, rocket assist, and gliding trajectories stretching ranges out to nearly $100 \mathrm{~km}$.

At the Electromagnetic Launch Symposium in May 2006 in Potsdam, Germany, MG Nadeau (Commander, US Army RDECOM) challenged the 
technical community to consider the viability of extremely long range artillery. In particular, he was interested in a system that could send projectiles over distances equivalent to one or more time zones. Since a time zone at $30^{\circ}$ latitude has a width of $1400 \mathrm{~km}$ or so, such an undertaking is daunting. While no program existed to provide such a capability, Schmidt [2] conducted a parametric study of possible electromagnetic (EM) railgun solutions to this challenge; however, the required launcher was not examined in detail. The present paper provides some of this information for one possible delivery system.

\section{Projectile}

EM guns are not rifled; thus, a statically stable projectile is considered. Fin stabilization is assumed; although it is recognized that aerodynamic heating may preclude such a scheme. The projectile, Figure 1, has a body diameter of $0.20 \mathrm{~m}$ and a length of $2.46 \mathrm{~m}$. The projectile has a tungsten nose to improve stability and provide some thermal protection. PRODAS [3] is used to compute inertial and aerodynamic properties. With allowances for batteries and guidance, the flight mass is $227 \mathrm{Kg}$ and the transverse and axial moments of inertia are 101 and $1.65 \mathrm{Kg}-\mathrm{m}^{2}$, respectively. The payload is $57 \mathrm{Kg}$. The center of gravity is 6.67 calibers from the nose, while the center of pressure is 6.94 calibers from the nose. With a static margin of 0.27 calibers, the projectile is barely stable; however, this may be advantageous in providing control authority to the guidance system.

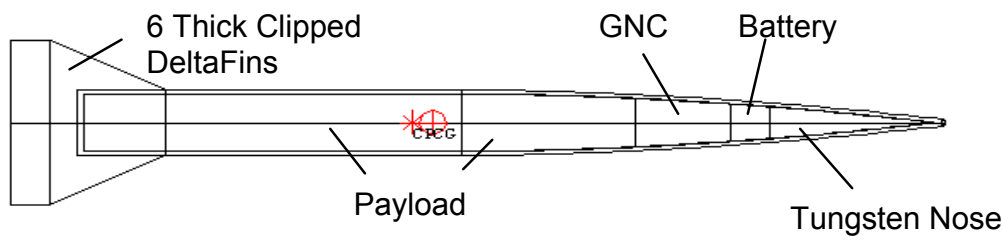

Figure 1: Schematic of notional projectile.

The muzzle velocity of interest is $4.0 \mathrm{~km} / \mathrm{s}$. At this velocity, the zero yaw drag coefficient is $\mathrm{C}_{\mathrm{Do}}=0.172$. Because of the long ranges considered, the trajectory of the projectile is computed using central body theory assuming an exponential atmosphere throughout the flight. At the $4.0 \mathrm{~km} / \mathrm{s}$ muzzle velocity and $50^{\circ}$ elevation, a range of $1176 \mathrm{~km}$ is estimated, Figure 2 . This velocity is well within the demonstrated capabilities of EM railguns using plasma armatures. For these launch conditions, a maximum altitude of nearly $400 \mathrm{~km}$ is obtained. Such a trajectory closely replicates that of an intermediate range ballistic missile. 


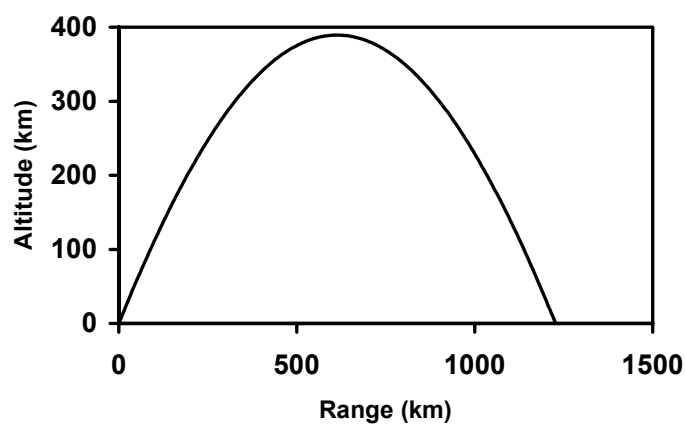

Figure 2: $\quad$ Trajectory for $\Theta=50^{\circ}, \mathrm{v}_{\mathrm{m}}=4 \mathrm{~km} / \mathrm{s}$.

\section{EM railgun launcher}

\subsection{General description}

The EM railgun accelerates the projectile under the influence of the Lorentz force, Figure 3. Current is passed down one rail, crosses over through the projectile armature, and returns through the opposing rail. The magnetic field, $\mathbf{B}$, generated by the two rails acts on the current in the armature, $\mathbf{J}$, to produce the $\mathbf{J} \times \mathbf{B}$ force. This purely electrical operation results in significant advantages compared to conventional cannon. An EM gun is capable of pushing projectiles to very high velocity. Values $6 \mathrm{~km} / \mathrm{s}$ and greater have been reported for light masses. Conventional cannon are limited by the free expansion velocity of the propellant gases, typically around $3.5 \mathrm{~km} / \mathrm{s}$. Practical considerations limit this to velocities of $1.8 \mathrm{~km} / \mathrm{s}$ or less. As the magnetic field acts on the armature, it also acts on the opposing rails resulting in a Lorentz force that will cause the rails to repel each other. Thus, confinement must be provided to hold the gun assembly together. For the purpose of describing the size and mass of the launcher, this confinement is given particular attention herein.

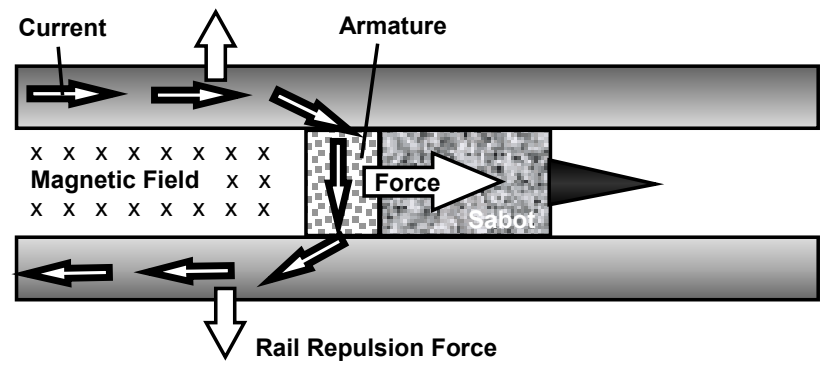

Figure 3: Schematic of a typical railgun. 
It is assumed that the launch package consists of the flight body, a base push armature, and a sabot to provide in-bore support to the projectile. Based on the action limit, it has been postulated [4] that a parasitic mass ratio (armature and sabot mass divided by total launch mass) of $25 \%$ is realizable. Thus, the total launch mass is taken to be $303 \mathrm{Kg}$. At $\mathrm{v}_{\mathrm{m}}=4.0 \mathrm{~km} / \mathrm{s}$, the resulting muzzle energy is 2.42 GJ. To provide clearance for the fins, the bore diameter is 0.525 $\mathrm{m}$. A circular bore geometry is assumed with a pair of GlidCop rails each having an $80^{\circ}$ included angle.

There are a number of constraints that must be considered in developing a design for the railgun. Among them are the acceleration tolerance of the payload, the projectile base pressure, the bore pressure relative to the yield strength of the bore materials, the rise in bulk bore temperature during the shot, and the current density to which the rails are exposed as the projectile passes. Available technology for projectile guidance systems limits maximum acceleration levels to less than $20 \mathrm{Kg}$.

For the projectile considered here, the maximum in-bore acceleration is selected to be $17.5 \mathrm{Kg}$, which allows the guidance system to survive and gives a maximum base pressure equivalent to that of conventional cargo carrying projectiles. Based on prior data from electromagnetic guns, a reasonable value for the acceleration ratio, average to peak, is 0.7 . This leads to an estimated bore length of $67 \mathrm{~m}$.

Brody [5] gives a relation for the rail temperature rise based on the electrical action to which the rails are exposed:

$$
\Delta \mathrm{T}=2\left[\rho_{\mathrm{e}} /\left(\rho_{\mathrm{m}} \mathrm{C}_{\mathrm{p}}\right)\right] \mathrm{mv}_{\mathrm{m}} / \mathrm{L}^{\prime} \mathrm{A}^{2}
$$

where $\rho_{\mathrm{e}}$ is electrical resistivity, $\rho_{\mathrm{m}}$ is material density, $\mathrm{C}_{\mathrm{p}}$ is heat capacity, $\mathrm{L}^{\prime}$ is the longitudinal inductance gradient, and $\mathrm{A}$ is rail cross-sectional area. From this relation, the rail thickness may be computed once an allowable temperature rise is selected and L' is known. To permit multiple shots to be fired without serious degradation of composite properties, $\Delta \mathrm{T}=20 \mathrm{~K}$ is selected. Since L' depends upon the rail thickness, an iterative process is required. As an initial estimate [6], $\mathrm{L}^{\prime}=0.5 \mu \mathrm{H} / \mathrm{m}$. These values result in an initial estimate of rail thickness, $\mathrm{t}=$ $82.5 \mathrm{~mm}$.

Ellis [7] has developed a model that integrates the electromagnetic fields surrounding the rails to obtain a value of L' and other properties of interest. The corrected value for the inductance gradient is $\mathrm{L}^{\prime}=0.57 \mu \mathrm{H} / \mathrm{m}$. This results in a thickness, $\mathrm{t}=77.8 \mathrm{~mm}$. Further iteration produces no perceptible change in L'.

An expression for the Lorentz force is $\mathrm{F}=1 / 2 \mathrm{~L}^{\prime} \mathrm{I}^{2}=$ ma. Knowing the launch mass, maximum acceleration, and L', the peak current is computed to be $\mathrm{I}_{\max }=$ 13.5 MA. Thus, the maximum current density at the armature location is 36.8 $\mathrm{kA} / \mathrm{mm}$, a value within the accepted limits for copper. McNab [4] calculates the back emf for a railgun launcher as $\mathrm{V}_{\text {back }}=I L{ }^{\prime} \mathrm{V}_{\mathrm{m}}$. For the present launcher, this predicts $\mathrm{V}_{\text {back }}=30.8 \mathrm{kV}$ yielding a maximum power required of $416 \mathrm{GW}$. These values imply a pulsed power supply of impressive capabilities and equally impressive size and mass. For space launch of a $1250 \mathrm{Kg}$ launch package at $\mathrm{v}_{\mathrm{m}}=$ $7.5 \mathrm{~km} / \mathrm{s}\left(\mathrm{E}_{\mathrm{m}}=35 \mathrm{GJ}\right), \mathrm{McNab}$ proposed using 100 pulsed alternators distributed 
along the $1600 \mathrm{~m}$ length of the earth-to-space launcher. Treatment of the power supply is beyond the scope of the present study; however, the details of the launcher structure are considered in the next section.

\subsection{Structural analysis}

The rails are copper and are separated by G10 (glass composite) insulators. The containment is assumed to be constructed with carbon composite hoop wound overwrap. In general, the stress magnitude and distribution can be adjusted by varying the thickness of rail and containment, the arc length of rails, and the stiffness ratio of the gun bore components. A finite element model, Figure 4, is built to calculate the stress profiles in the bore. The rail, insulator, and containment are shown in the region of blue, orange, and gray, respectively. The rail thickness is $77.8 \mathrm{~mm}$ ( $3 \mathrm{in}$ ) and the containment thickness is $127 \mathrm{~mm}$ (5 in). Based on these thickness and material assumption, the structural analysis showed the gun bore can be designed and built with reasonable engineering effort.

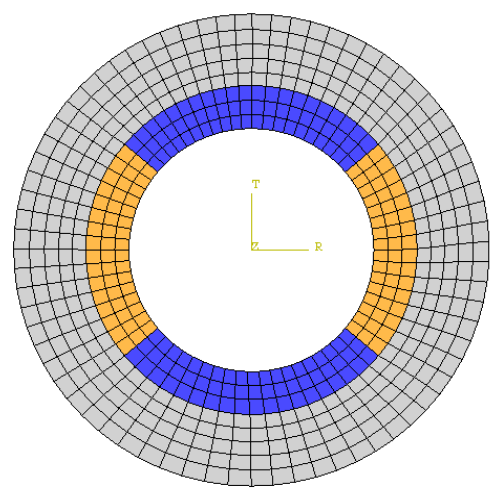

Figure 4: $\quad$ Finite element model of the gun bore.

Hoop, radial, and shear stress profiles are illustrated in Figures 5-7, respectively. The stress profiles are plotted in English units (i.e. psi). The maximum tensile hoop stress of $630 \mathrm{MPa}(90 \mathrm{ksi})$ is located in the inner radius of rails. Accordingly, the combined hoop and radial stress at the inner radius is critical since it is assumed that a $140 \mathrm{MPa}(20 \mathrm{ksi})$ magnetic pressure is applied on the surface. The combined stress is in excess of the $517 \mathrm{MPa}$ yield of GlidCop; however, evolving alumina particle reinforced coppers may be available to meet the strength requirement. In actuality, the magnetic force is distributed through the entire rail thickness and can only be determined by more detail electromagnetic analysis. The hoop stress at the inner radius of insulator is $525 \mathrm{MPa}(75 \mathrm{ksi})$ in compression. It may be critical for commonly used material such as G10, various materials or insulator designs can mitigate these stress problems. 

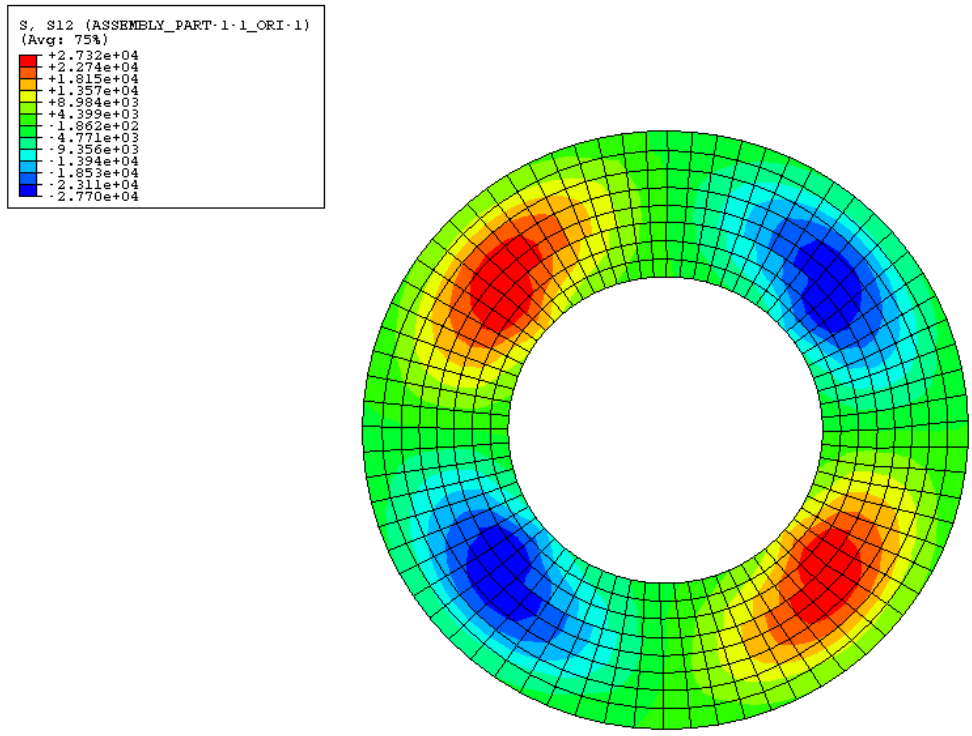

Figure 7: Shear stress profile in the gun bore.

The radial stress is manageable but shear stress is critical in this gun bore design. It is about $175 \mathrm{MPa}(25 \mathrm{ksi})$ in the region of the rail/insulator interfaces. It is slightly high for composite materials ( $\mathrm{G} 10$ and carbon composite). However, it again can be mitigated by using different material or varying the composite fiber architecture and thickness.

When a high strength, hoop wound carbon composite containment is used, the hoop stresses in the containment are quite manageable. A shortcoming of the gun tube may be a lack of the axial strength and stiffness; however, the addition of external truss should provide the axial requirement. This preliminary evaluation of the rail gun design shows that a functional gun bore design can be achieved.

\subsection{Launcher dimensions}

To show the scale of the launcher, a comparison between the EM Long Range Artillery Launcher and the World War II German Gun, Gustav, is presented in Figure 8. The EM launcher is roughly twice as long as Gustav, but has a bore of $525 \mathrm{~mm}$ compared to $800 \mathrm{~mm}$. The outer diameters of the two cannon are roughly equal. Given its length, the EM launcher will require an external truss work to provide stiffness against droop. The Paris Gun of World War II used such a truss. From the structural analysis, the weight of the EM gun tube is calculated to be $77,560 \mathrm{Kg}$ given a length of $66.6 \mathrm{~m}$. This is significantly less massive that Gustav which weighed in at $364,000 \mathrm{Kg}$. 
The recoil system is an important consideration in determining overall size and mass. Gustav launched a $4800 \mathrm{Kg}$ projectile to a velocity of $820 \mathrm{~m} / \mathrm{s}$ using roughly $704 \mathrm{Kg}$ of propellant. This results in a recoil impulse of $4.22 \times 10^{6} \mathrm{~N}$-s. Surprisingly, the longer EM launcher firing a $303 \mathrm{Kg}$ projectile at $4.0 \mathrm{~km} / \mathrm{s}$ has a lower recoil impulse of $1.21 \times 10^{6} \mathrm{~N}$-s. Thus, the size and mass of the recoil system and overall cannon mount could be less for the EM launcher than for Gustav. Of course, the power supply must be given consideration. For Gustav, it consisted of the propellant needed for each shot. For the EM launcher, a rather substantial array of pulsed alternators or capacitors would be needed. Depending upon the number of rounds to be fired, the volume of the pulsed power supply could be offset by the reduction in propellant. Of course, Gustav only fired a total of 48 rounds in anger.

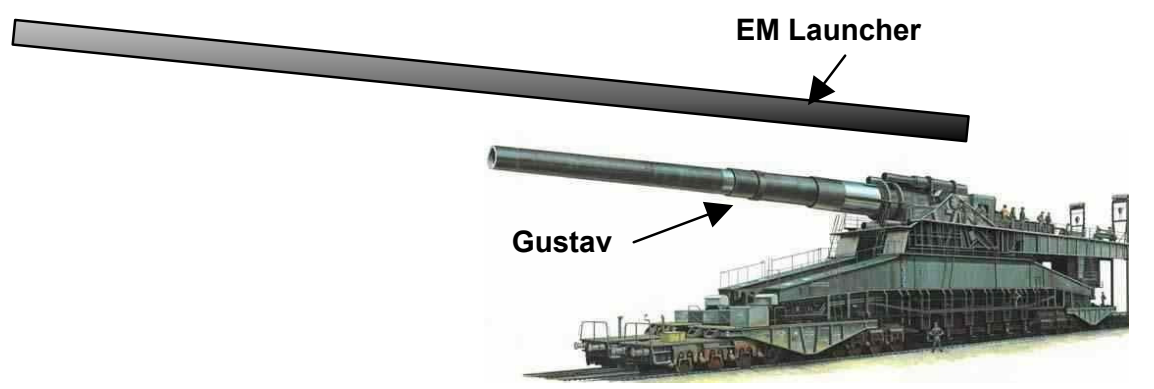

Figure 8: $\quad$ Relative scales of EM launcher and $800 \mathrm{~mm}$ Gustav cannon.

\section{Conclusions}

A study is presented to examine the launcher required to electromagnetically fire a projectile to very long range. The scale of the launcher is prodigious, generally larger than any known gun capable of transport or elevation. Although not addressed in this paper, the pulsed power supply needed to drive the launcher is also a challenge.

\section{References}

[1] Hogg, I., Twentieth-Century Artillery, Amber Books, London, 2000.

[2] Schmidt, E., Aerodynamic Aspects of Hypervelocity Projectiles, Proceedings of the $23^{\text {rd }}$ International Symposium on Ballistics, Tarragona, Spain, April 2007.

[3] PRODAS 2000, Arrowtech Associates, Burlington, VT, (2000).

[4] McNab, I., Launch to Space with an Electromagnetic Railgun, IEEE Transactions on Magnetics, 39, (2003).

[5] Brody, J., Theoretical Design and Modeling of an Infantry Railgun Projectile, Thesis, Naval Postgraduate School, Monterey, CA, 2005. 
[6] Werst, M., Cook, K., Kitzmiller, J., Liu, H., Price, J., and Yun, H., Design and Testing of a Rapid Fire, Lightweight, Ultra Stiff Railgun for a Cannon Caliber Electromagnetic Launcher System, IEEE Transactions on Magnetics, 31 (1995).

[7] Ellis, R., Private Communication, ONR, Rosslyn, VA, February 2007. 